\title{
Real time earthquake hazard map of liquefaction in Korea
}

\author{
Jae-Soon Choi ${ }^{\text {i) }}$, Woo-Hyun Baek ${ }^{\text {ii) }}$ and Oh-Gyu Kwon ${ }^{\text {iii) }}$ \\ i) Assistant Professor, Department of Civil \& Architectural Engineering, Seokyeong University, 124, Seokyeong st, Seongbuk 136-704, \\ Korea. \\ ii) Graduated Student, Department of Urban \& Environmental System Engineering, Seokyeong University, 124, Seokyeong st, \\ Seongbuk 136-704, Korea. \\ iii) Graduated Student, Department of Urban \& Environmental System Engineering, Seokyeong University, 124, Seokyeong st, \\ Seongbuk 136-704, Korea.
}

\begin{abstract}
The purpose of this study was to create a real-time liquefaction hazard map at national level by taking into consideration the differences between the site acceleration and intensity scale distribution depending on the occurrence site when an earthquake would take place. To this end, the two sub-studies were conducted. The first was to create a liquefaction hazard map for each site acceleration for an earthquake based on the evaluation method of macro-liquefaction for each site acceleration. The second was to establish a real-time liquefaction hazard map DB that could be linked with the system for earthquake disaster prevention by integrating the liquefaction hazard maps of all the site accelerations. First, this study conducted the liquefaction evaluation by developing the metropolitan area liquefaction evaluation program based on Excel in order to use approximately 14,040 metropolitan area site data. This study deducted the Liquefaction Potential Index (LPI) for each site depth by using the correction Seed \& Idriss method and the site amplification coefficient satisfying South Korea's earthquake-resistant criteria in relation to the liquefaction evaluation. This metropolitan area liquefaction evaluation program is able to skip the site response analysis for earthquake used when creating a facility-centric hazard map in order to create a liquefaction hazard map at city, provincial and national levels. Also, this metropolitan area liquefaction evaluation program is able to substitute it with a site amplification coefficient in order to reduce the duration of liquefaction evaluation. As a result, it was possible to reduce the time taken to create a liquefaction hazard map by approximately 50,000 hours. In the end, the liquefaction hazard map for each site acceleration was created based on the interval of $0.04 \mathrm{~g}$ from $0.06 \mathrm{~g}$ to $0.38 \mathrm{~g}$. In regard to the second sub-task that was to create a real-time liquefaction hazard map, the basemap that would become a basis of creating a liquefaction hazard map was designed to be linkable after using the cell unit of $2 \mathrm{Km}$ by $2 \mathrm{Km}$ used by the system for earthquake disaster prevention. Then, this study deducted the relational formula through the earthquake acceleration for each coordinate and the correlation with LPI. At this time, the optimal relational formula was applied in relation to LPI for each site acceleration and the correlation between the relational formulas among those two-variable 4 relational formulas. For the verification of this study, a real-time liquefaction hazard map of earthquake scale 6.0 was created in consideration of the difference in the site distribution for an earthquake as to Hongseong Earthquake and Odae-mountain Earthquake, which took place previously.
\end{abstract}

Keywords : Liquefaction, Real-time liquefaction hazard map, Amplification coefficient, LPI

\section{INTRODUCTION}

Recently, there was the news about minimizing the earthquake damage in the neighboring region by ceasing various lifelines and preparing for emergency response through the alarm from the Earthquake Early Warning System (EEWS) of the UC Berkeley Earthquake Research Institute 10 seconds after the occurrence of Napa Earthquake. Many reports have been continuously reported on the scope of damage resulting from liquefaction phenomenon caused by such seismic motion as an earthquake. Some of the aforementioned reports are the damage case reports about the Northeast Earthquake of Japan and the Christchurch Earthquake of New Zealand, both of which took place in 2011. In this regard, not only those earthquake-prone countries such as the United States and Japan but also all the countries around the world make it mandatory to first review thereon in relation to earthquake-resistant design. In fact, they have established and used a national liquefaction hazard map for preparing a countermeasure. Currently, South Korea is also making a lot of efforts to establish and advance the system for earthquake disaster prevention at 
national level. This study conducted the two sub-researches in order to create a real-time liquefaction hazard map using the metropolitan area site information. First, a liquefaction evaluation program was developed in Excel in order to process a large quantity of site data in the metropolitan areas including Seoul, Incheon and Gyeonggi-do. Also, this study created a liquefaction hazard map for each site acceleration based on the interval of $0.04 \mathrm{~g}$ from $0.06 \mathrm{~g}$ to $0.38 \mathrm{~g}$ with the use of the developed liquefaction evaluation program. Second, this study proposed a relational formula as to those individual coordinates in the unit of cell on the map through LPI an the correlation for each site acceleration in relation to the creation of a liquefaction hazard map for each site acceleration. Finally, this study created a real-time liquefaction hazard map that could be linked with the system for earthquake disaster prevention and then compared this with the liquefaction hazard map for each site acceleration.

\section{DEVELOPMENT OF LIQUEFACTION EVALUATION PROGRAM}

To process approximately 14,040 site data, this study conducted the liquefaction evaluation by developing a liquefaction evaluation program using the amplification coefficients for each site that could reduce the time taken for liquefaction evaluation rather than using the numerical analysis program such as Proshake that was the facility-centric liquefaction evaluation method. At this time, this study utilized Liquefaction Potential Index (LPI) proposed by Iwasaki in relation to the liquefaction evaluation for each site acceleration. Also, this study placed priority on the creation of a liquefaction hazard map for each site acceleration as to the metropolitan areas using LPI. Fig. 1 shows the liquefaction evaluation program developed in Excel.

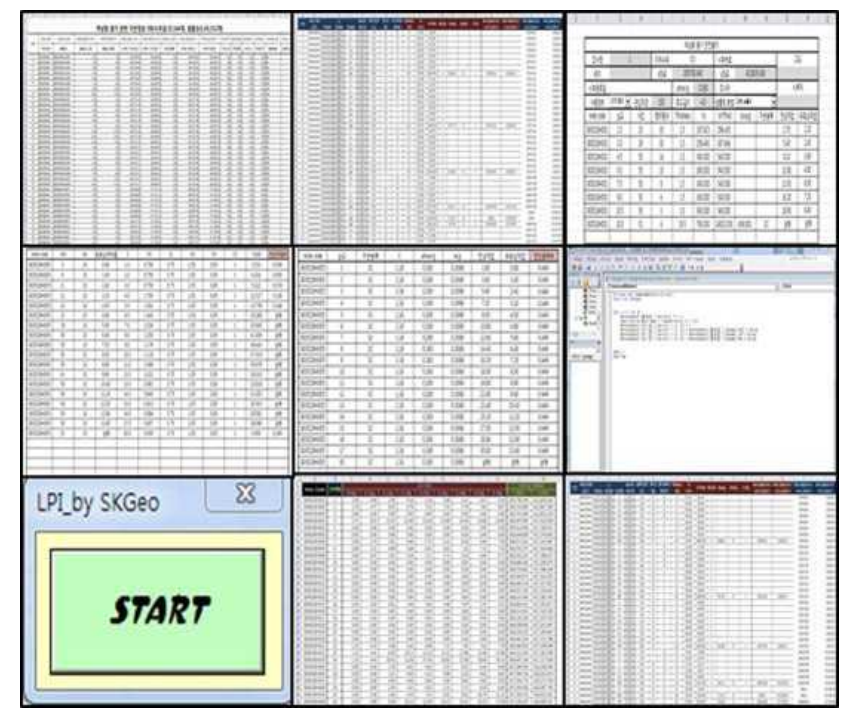

Fig. 1. Liquefaction evaluation program in Excel
As for the liquefaction evaluation method, this study conducted the liquefaction evaluation using the correction Seed \& Idriss and the site amplification coefficients satisfying South Korea's earthquake-resistant design. At this time, this study utilized SPT-N Value as site data. Table 1 shows the amplification coefficients for each site type recommended in South Korea.

Table 1. Amplification coefficient of Koran and Europe (Ministry of Construction and Transportation, seismic design criteria II 1997)

\begin{tabular}{c|c|c}
\hline \multirow{2}{*}{ Soil classification } & \multicolumn{2}{|c}{ Site Amplification Coefficient } \\
\cline { 2 - 3 } & Korea & Euro-code \\
\hline \hline$S_{A}$ & - & - \\
\hline$S_{B}$ & 1.00 & 1.00 \\
\hline$S_{C}$ & 1.18 & 1.14 \\
\hline$S_{D}$ & 1.45 & 1.45 \\
\hline$S_{E}$ & 2.00 & 2.00 \\
\hline$S_{F}$ & \multicolumn{2}{|c}{ Site Response Analysis } \\
\hline \multicolumn{2}{|c}{}
\end{tabular}

\section{CREATION OF REAL-TIME LIQUEFACTION HAZARD MAP}

To create a real time liquefaction hazard map at national level, it is imperative to conduct correlation analysis with the site acceleration resulting from the difference between LPI scale for each acceleration and the site distribution in accordance with the earthquake epicenter and then link the suitable formulas therefor to the representative point of each coordinate. This study proposed the most appropriate formula for the tendency by leveraging the 4 kinds of quadratic functional formula in order to calculate LPI relational formula for each location in accordance with the intensity scale distribution.

\subsection{Calculation of Relational Formula for Each Location}

This study conducted tendency analysis by selecting hyperbolic function, root function, linear fit and log function with quadratic function-relational equation. $\mathrm{Y}=$ location was set as LPI scale as to a total of 9 site accelerations based on the interval of $0.04 \mathrm{~g}$ with $\mathrm{x}$ of $0.06 \mathrm{~g}$ to $0.38 \mathrm{~g}$. This study conducted tendency analysis of each relational equation by using the randomly extracted 71 sample data (10 percent) from the 707 representative values. The results of the analysis are as shown in Table 2.

Table 2. Priority analysis of Function

\begin{tabular}{c|c|c|c|c|c}
\hline $\begin{array}{c}\text { Type of } \\
\text { Trend }\end{array}$ & $\begin{array}{c}\text { Name of } \\
\text { Trend }\end{array}$ & Equation & r(avg) & $r^{2}(\mathrm{avg})$ & SE(avg) \\
\hline \hline $\begin{array}{c}\text { 2nd } \\
\text { degree }\end{array}$ & $\begin{array}{c}\text { Hyperbolic } \\
\text { Fit }\end{array}$ & $y=a+b / x$ & 0.98104 & 0.96290 & 1.54143 \\
\hline
\end{tabular}




\begin{tabular}{|c|c|c|c|c|c|}
\hline \multirow[t]{3}{*}{ function } & Root Fit & $y=a b^{(1 / x)}$ & 0.94658 & 0.92935 & 1.39884 \\
\hline & $\begin{array}{c}\text { Logarithm } \\
\text { Fit }\end{array}$ & $y=a+b \ln (x)$ & 0.98346 & 0.96732 & 1.43561 \\
\hline & Linear Fit & $y=a+b x$ & 0.93422 & 0.87377 & 3.26686 \\
\hline \multirow{4}{*}{ Ranking } & $\begin{array}{c}\text { Hyperbolic } \\
\text { Fit }\end{array}$ & $y=a+b / x$ & 2 & 2 & 3 \\
\hline & Root Fit & $y=a b^{(1 / x)}$ & 3 & 3 & 1 \\
\hline & $\begin{array}{c}\text { Logarithm } \\
\text { Fit }\end{array}$ & $y=a+b \ln (x)$ & 1 & 1 & 2 \\
\hline & Linear Fit & $y=a+b x$ & 4 & 4 & 4 \\
\hline
\end{tabular}

Herein, $\boldsymbol{r}$ represents correlation coefficient, whereas $r^{2}$ represents coefficient of determination and SE refers to standard error. Also, Rea \& parker et al. (2005) argued that $r^{2}$ of 0.8 or higher would be a perfect positive linear relationship.

As a result of analyzing the sample of 10 percent, there was a high degree of correlation coefficient in hyperbolic function and log function. Thus, this allows us to know that it shows a similar pattern to the extracted LPI. On that account, this study conducted tendency analysis with all of the 707 representative values as to these two cases. The results thereof are as shown in Fig. 2 and Table 3.

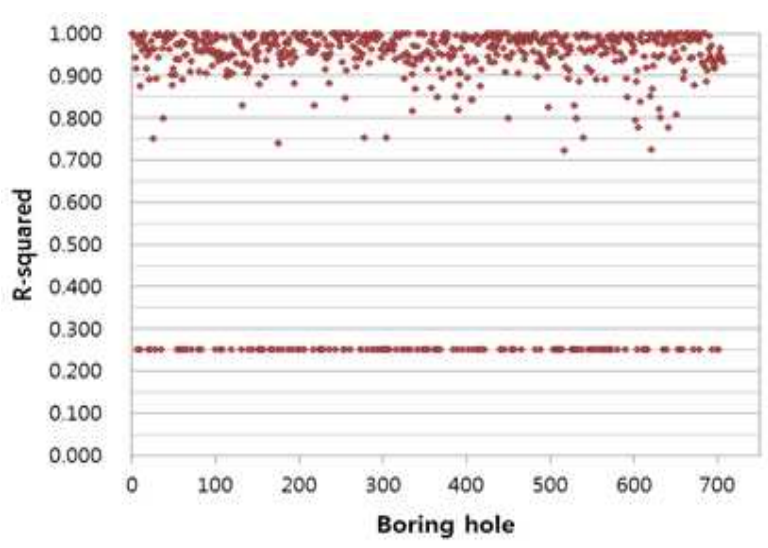

(a) Hyperbolic function

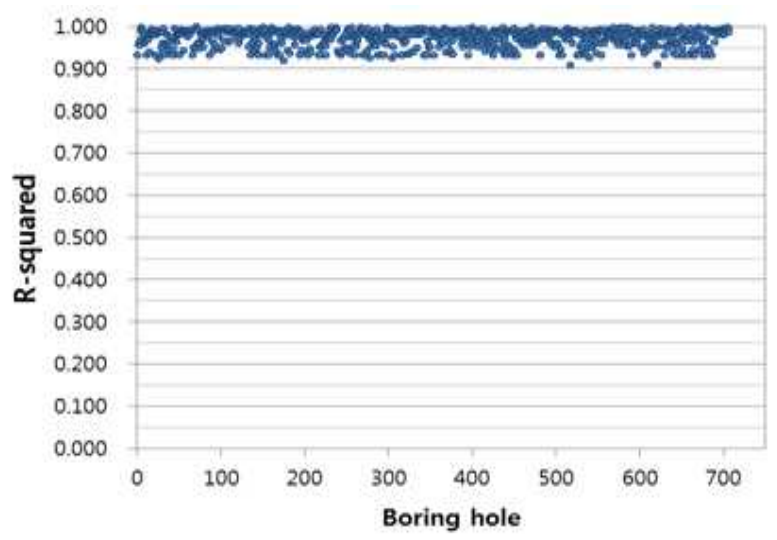

(b) Logarithm function

Fig. 2. Coefficient of determination graph
Table 3. Priority analysis of hyperbolic \& logarithm function

\begin{tabular}{c|c|c|c|c|c|c}
\hline $\begin{array}{c}\text { Name of } \\
\text { Trend }\end{array}$ & $\mathbf{r}(\mathrm{avg})$ & $\mathbf{r}^{2}$ (avg) & $\begin{array}{c}\text { SE } \\
\text { (avg) }\end{array}$ & $\begin{array}{c}\text { Ranking } \\
\text { of } \mathrm{r}(\mathrm{avg})\end{array}$ & $\begin{array}{c}\text { Ranking } \\
\text { of } \mathrm{r}^{\wedge} \text { 2(avg) }\end{array}$ & $\begin{array}{c}\text { Ranking } \\
\text { of SE(avg) }\end{array}$ \\
\hline \hline $\begin{array}{c}\text { Hyperbolic } \\
\text { Fit }\end{array}$ & 0.89079 & 0.82814 & 3.04015 & 2 & 2 & 2 \\
\hline $\begin{array}{c}\text { Logarithm } \\
\text { Fit }\end{array}$ & 0.98563 & 0.97157 & 1.69254 & 1 & 1 & 1 \\
\hline
\end{tabular}

Fig. 2 and Table 3 show that $\log$ functional formula has more reliable results than hyperbolic functional formula. For more specific visual comparison, this study compared the LPI value obtained by the liquefaction evaluation program for metropolitan area with the LPI value calculated from the two aforementioned functional formulas.

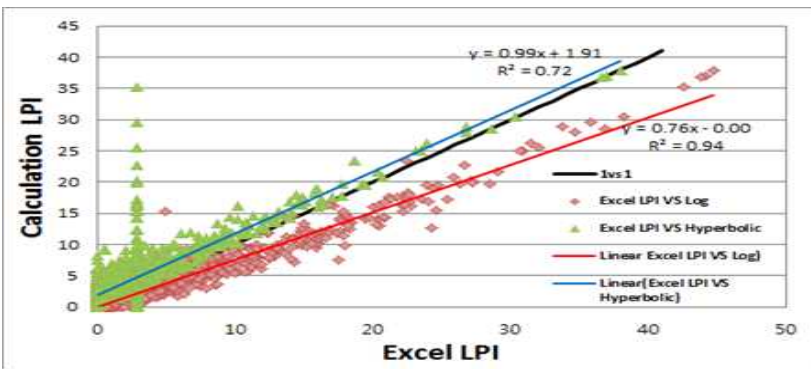

Fig. 3. Comparison of graph Excel LPI \& Calculation LPI 0.06g

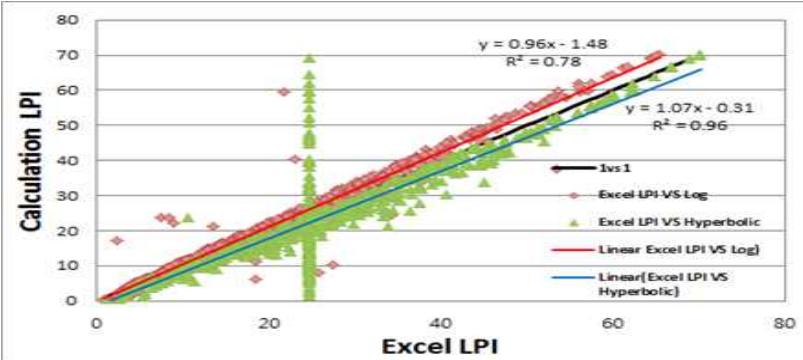

Fig. 4. Comparison of graph Excel LPI \& Calculation LPI 0.14g

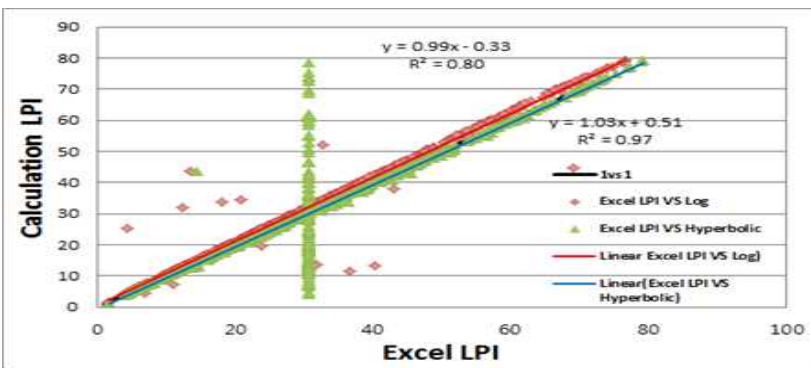

Fig. 5. Comparison of graph Excel LPI \& Calculation LPI 0.22g

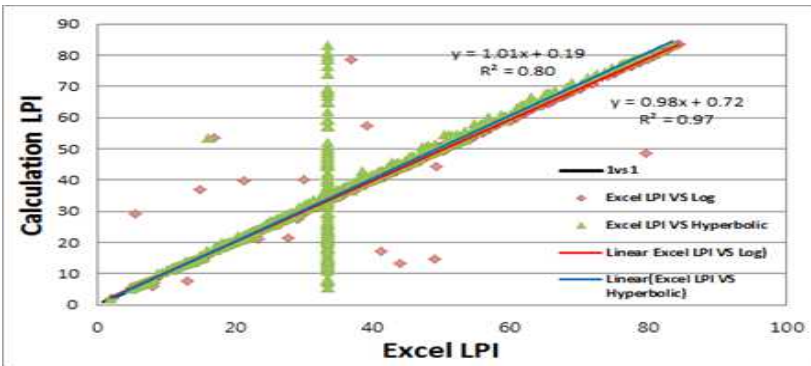


Fig. 6. Comparison of graph Excel LPI \& Calculation LPI 0.30g

It is possible to confirm through Fig. 3, Fig. 4, Fig. 5 and Fig. 6 that the LPI value obtained by log functional formula and hyperbolic functional formula would follow the similar pattern as to the actual LPI value. Hyperbolic functional formula gets closer to the actual LPI value at $0.06 \mathrm{~g}$. However, it was found that $\log$ functional formula was converged more with the actual value with an increase in the site acceleration. Therefore, this study selected log functional formula as a relational equation to create a real-time liquefaction hazard map.

\subsection{Comparison between liquefaction hazard map of liquefaction Excel program LPI for metropolitan and liquefaction hazard map of LPI with relational formula}

This study compared the liquefaction hazard maps of LPI calculated by using the above-calculated log functional formula with the one of LPI deducted from the liquefaction Excel program for metropolitan area through the figures.

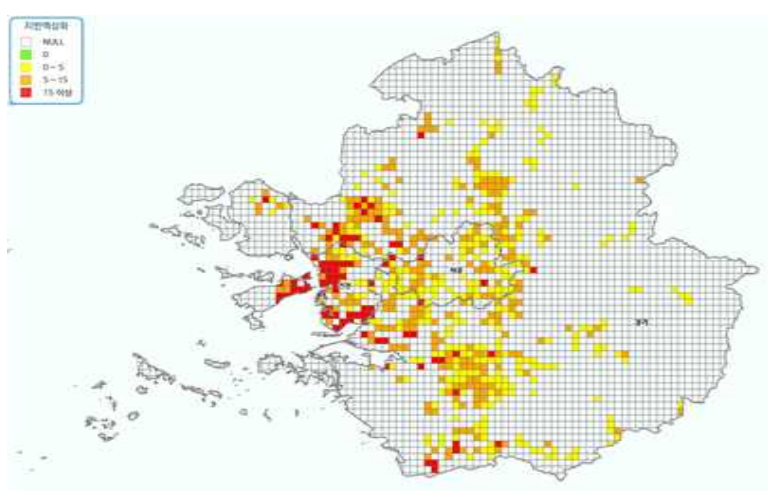

(a) Liquefaction hazard map using calculation formula

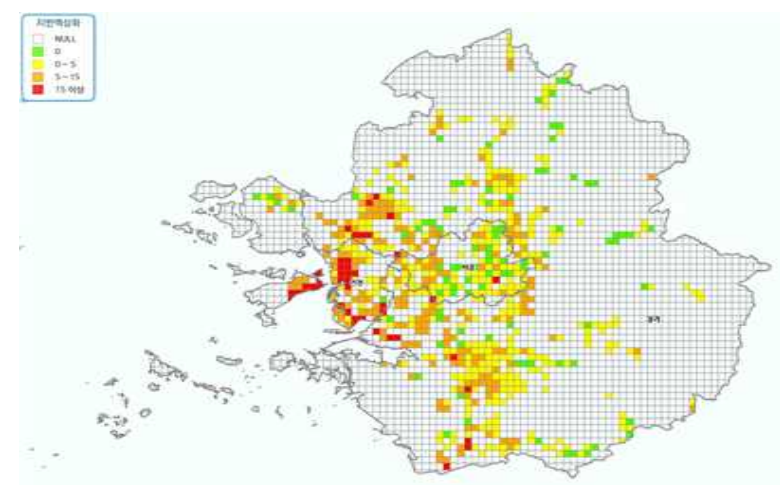

(b) Liquefaction hazard map using excel program result value

Fig. 7. PGA $0.06 \mathrm{~g}$

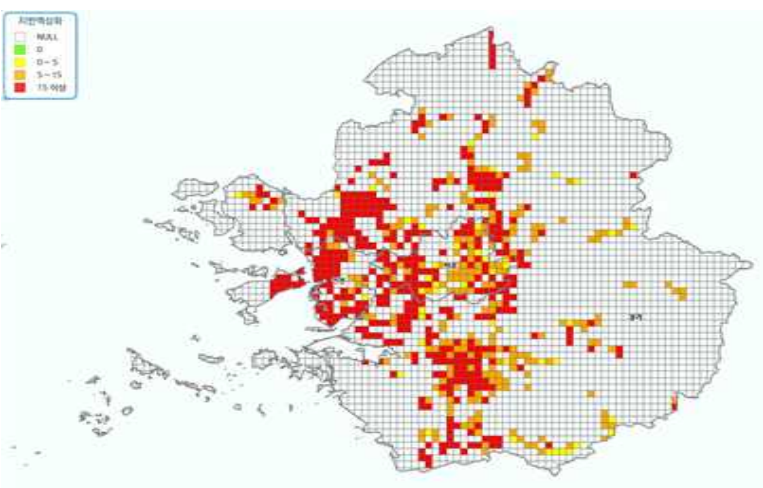

(a) Liquefaction hazard map using calculation formula

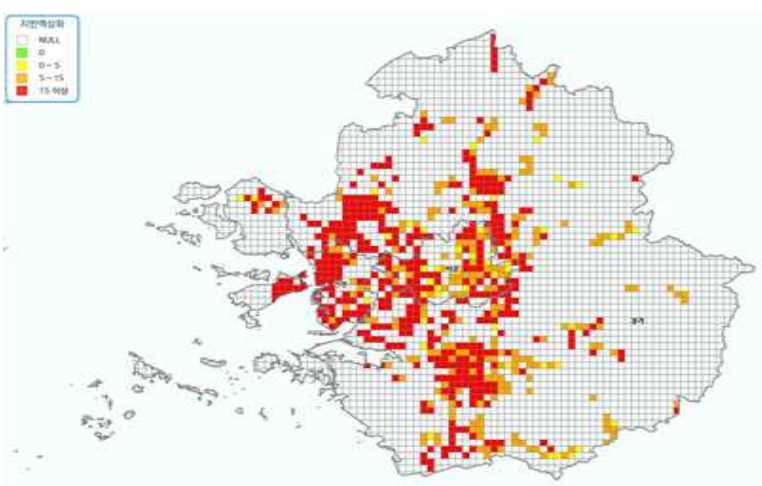

(b) Liquefaction hazard map using excel program result value Fig. 8. PGA $0.14 \mathrm{~g}$

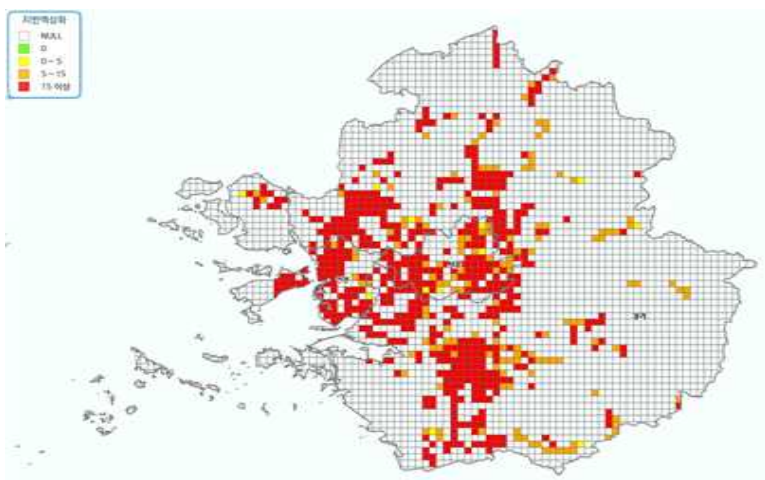

(a) Liquefaction hazard map using calculation formula

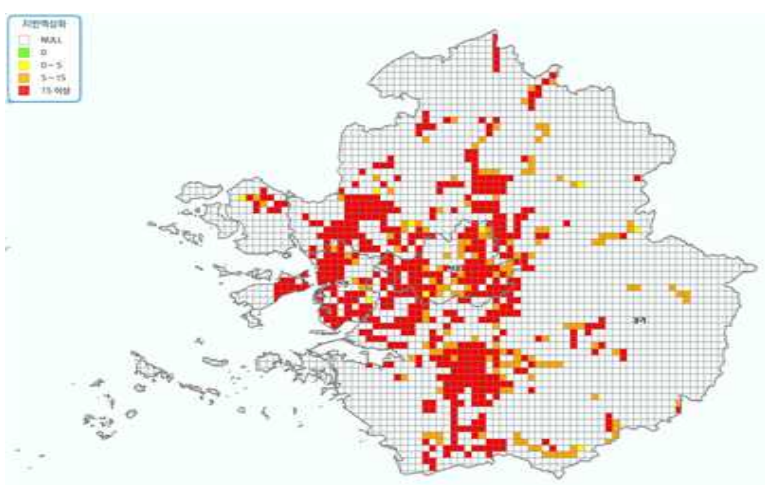

(b) Liquefaction hazard map using excel program result value Fig. 9. PGA $0.22 \mathrm{~g}$ 


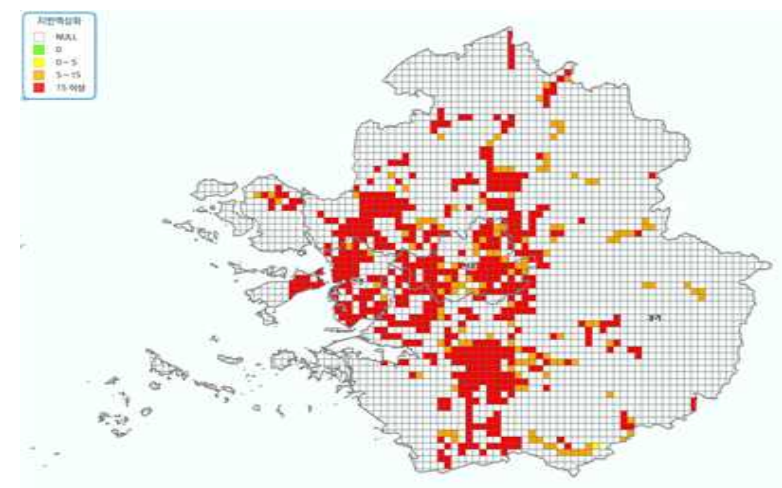

(a) Liquefaction hazard map using calculation formula

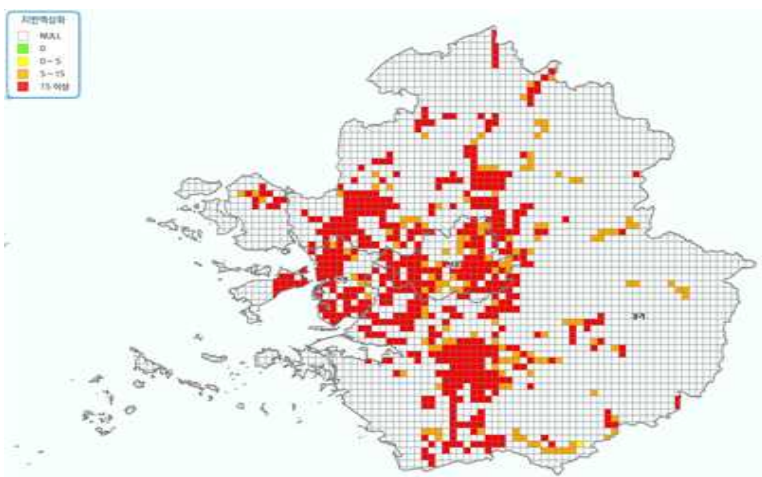

(b) Liquefaction hazard map using excel program result value

Fig. 10. PGA 0.30g

The metropolitan area liquefaction hazard map of each site acceleration as shown in Fig. 7, Fig. 8, Fig. 9 and Fig. 10 indicates that the LPI that was calculated as a relational formula at $0.06 \mathrm{~g}$ would be shown excessively as compare with the LPI deducted from the liquefaction Excel program for metropolitan area. However, it is possible to know that a hazard map will have more similar tendency with an increase in the site acceleration. Thus, this study aims to propose log functional formula (1) for the creation of a real-time liquefaction hazard map in consideration of safety rate.

$$
y=a+b \ln (x)
$$

Herein, $\boldsymbol{a}$ and $\boldsymbol{b}$ are unknown variable values derived from tendency analysis, whereas $\boldsymbol{x}$ represents site acceleration and $\boldsymbol{y}$ represents LPI value.

\section{MOCK EVALUATION SIMULATION OF REAL-TIME LIQUEFACTION HAZARD MAP}

The Hongseong Great Earthquake that took place in Hongseong-eup of Chungcheongnam-do around 6 PM on October 71978 and the Odae-mountain Earthquake that took place on January 202007 are the largest earthquakes to be observed in the inland since the digital earthquake observatory of Korea Meteorological Administration was established. This study conducted simulation on the earthquake of intensity scale 6 with Hongseong and Odae-mountain as the epicenter through $\log$ functional formula proposed in the preceding page and the system for earthquake disaster prevention. Fig. 10 shows the case of intensity scale 6.0 for the Hongseong Earthquake and Fig. 11 shows the case of intensity scale 6.0 for the Hongseong Earthquake.

From Fig. 11 and Fig. 12 of liquefaction hazard map based on the values derived from using log functional formula proposed through the correlation between LPI and site acceleration using the real-time liquefaction hazard map allow us to find out indirectly that the intensity scale distribution varies depending on the epicenter and there are many differences in the site acceleration between the regions.

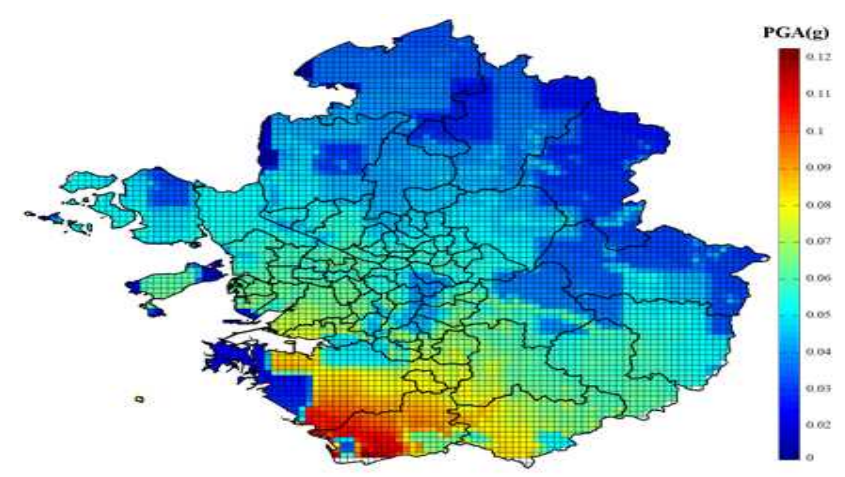

(a) PGA M 6.0

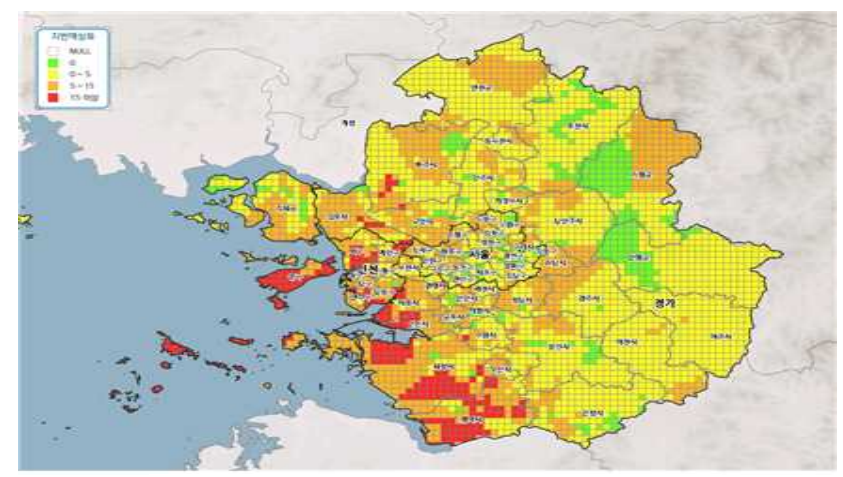

(b) Real time liquefaction hazard map M 6.0

Fig. 11. Liquefaction hazard map of the epicenter located in Hongsung

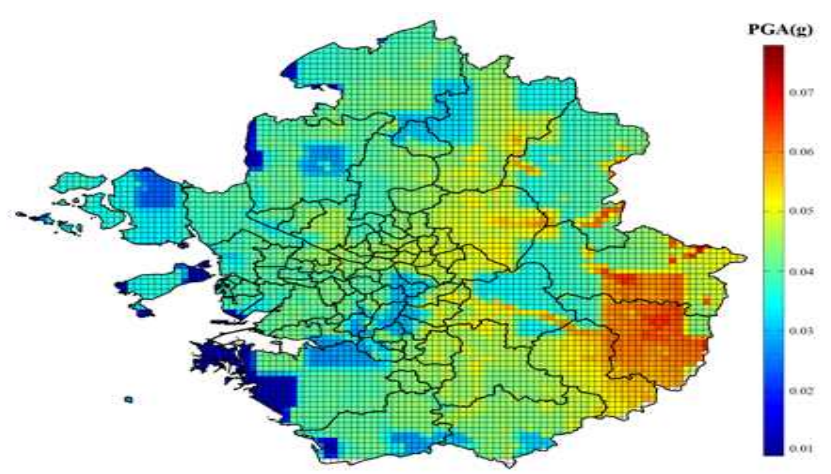

(a) PGA M 6.0 


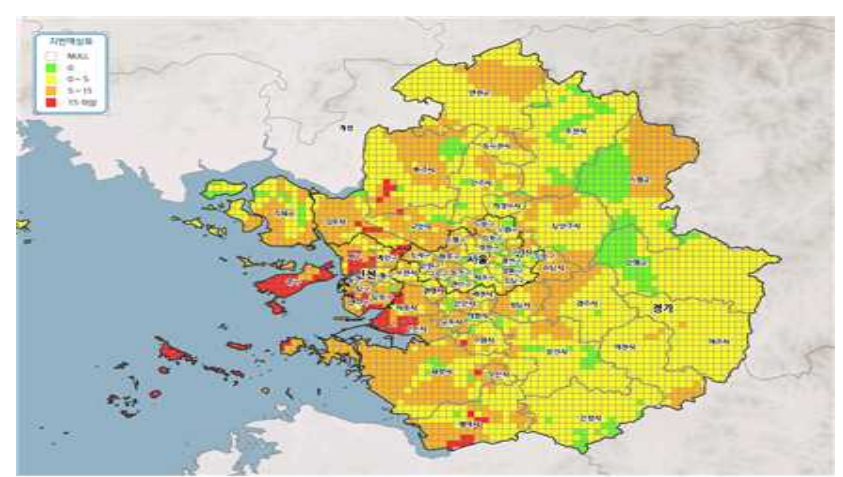

(b) Real time liquefaction hazard map M 6.0

Fig. 12. Liquefaction hazard map of the epicenter located in Odaesan

\section{CONCLUSIONS}

This study conducted liquefaction evaluation by developing the liquefaction evaluation program for metropolitan area using the site amplification coefficients. For real-time linkage, this study proposed the relational formula through the correlation between LPI and site acceleration. The main results of this study are summarized as follows.

(1) This study created a liquefaction hazard map for the metropolitan areas (Seoul, Incheon and Gyeonggi-do) for each site acceleration by developing a liquefaction evaluation Excel program for metropolitan area using the amplification coefficients for each site type rather than the liquefaction evaluation method accompanying site response analysis. This program is able to reduce the performance time significantly since its performance process is simple. Moreover, it is believed that this program is suitable for performing a liquefaction evaluation for metropolitan area because updated data will also be useful when the site information at the Integrated DB Center of National Geotechnical Information is updated.

(2) This study created a liquefaction hazard map by proposing a relational formula through the correlation between the site acceleration and Liquefaction Potential Index in order to create a real-time liquefaction hazard map that could be linked to the system for earthquake disaster prevention. In addition, this study created and compared the liquefaction hazard map for each site acceleration with the liquefaction hazard map through relational formula. As a result of the analysis, the liquefaction hazard map through relational formula from $0.06 \mathrm{~g}$ to $0.10 \mathrm{~g}$ showed that the liquefaction hazard map index was high, whereas the liquefaction hazard map through relational formula from $0.14 \mathrm{~g}$ to $0.38 \mathrm{~g}$ showed a similar tendency. Consequently, it would be possible to prepare a conservative countermeasure that would derive a somewhat high safety rate.
(3) It is believed that it would be advantageous for creating a liquefaction hazard map that would be linked to a national liquefaction hazard map in real-time for the future based on the liquefaction evaluation Excel program for metropolitan areas that was developed in this study and also through the proposed log formula.

\section{ACKNOWLEDGEMENTS}

This research was supported by a grant 'Development of Prediction Method for Ground Failures Including Earthquake Induced Slope in stability' [NEMA-NH-2012-12] from the Natural Hazard Mitigation Research Group, National Emergency Management Agency of Korea.

\section{REFERENCES}

1) Baek, W. H. (2014): Development of Real Time Liquefaction Hazard Map Using Metropolitan Area Site Information Data, Master dissertation, University of Seokyeong, Seoul, Korea. (in Korean)

2) European Committee for Standardization (1998): Eurocode8, European Committee for Standardization, Brussels, Belgium, pp. 33-35.

3) Iwasaki, T., Tatsuoka, K., Tokida, F. and Yasuda, S. (1978a): A Practical Method for Assessing Soil Liquefaction Potential Based on Case Studies at Various Sites in Japan, Proceedings of 2nd International Conference on Microzonation, National Science Foundation UNESCO, San Francisco, C.A., Vol. 2, pp. 885-896.

4) Iwasaki, T., Tokida, F., Tatsuoka, K., Watanabe, S. and Yasuda, S. (1978b): Microzonation for Soil Liquefaction Potential using Simplified Methods, Proceedings of 2nd International Conference on Microzonation, National Science Foundation UNESCO, Seattle, W.A., pp. 1319-1330.

5) Japanese Geotechnical Society. (1999): Manual for Zonation on Seismic Geotechnical Hazards (Revised Version), ISSMGE Technical Committee for Earthquake Geotechnical Engineering, TC4, Tokyo, Japan, Toushin insatsu Co.,Ltd.

6) Kim, S. I., Park., I. J. and Choi, J. S. (2000): A Study on the Assessment of Liquefaction Potential in Korea, Journal of Korean Society of Civil Engineers, KSCE, Vol. 20, No. 2-C, pp. 129-139. (in Korean)

7) Korean Geotechnical Society (2010): Understanding on Site Response Analysis from Round Robin Test, KGS (technical committee of soil dynamics and earthquake geotechnical engineering) special publication No. 2, Seoul, Korea, Koomiseokwan. (in Korean)

8) Rea, L. M., \& Parker, R. A. (2005): Designing and conducting survey research, A comprehensive guide, SanFrancisco, CA, Jossey-Bass.

9) Seed, H. B., Tokimatsu, K. and Harder, L. F. (1985): Influence of SPT Procedures in Soil Liquefaction Resistance Evaluation, Journal of Geotechnical engineering, ASCE, Vol. 111, No.12, pp.1425-1445.

10) Sun. C. K., Jeong, C. K. and Kim, D. S. (2005): A Proposition of Site Coefficients and Site Classification System for Design Ground Motions at Inland of the Korean Peninsula, Journal of Korean Geotechnical Society, KGS, Vol. 21, No. 6, pp. 101-115. (in Korean) 